\title{
BOOKS AND REPORTS REVIEWED
}

Health Education in Rural Schools. J. Mace Andress, Ph. D. Boston: Houghton Mifflin Company. 1919. Pp.121+viii. Price, \$1.60.

The importance of health education and protection of school children is thoroughly established. It is recognized that the future health and vigor of the race depend on the proper care and instruction of the children today. The vast number of men rejected in the first draft because of physical defects would indicate that much can be done to recognize early physical defects, and to correct them while they are not very serious. Medical inspection and public health nursing among school children are spreading in our cities today, but the movement has hardly even obtained a foothold in the rural schools. Yet it is in these schools where health protection and education seem to be particularly necessary. The purpose of this book is to emphasize the subject of health protection and education of rural school children, and to place before the teacher in the rural schools, a text-book which may serve as a guide and stimulus in this part of her work.

There are many sanitary defects in the rural schools. The lighting is usually bad; the seats and desks are non-adjustable; the school buildings are poorly heated; the water is obtained from shallow wells and springs which are often polluted; the open bucket and common drinking cup are used; the doors and windows are seldom screened; and the toilet facilities are exceedingly bad. The rural schools are also deficient in medical inspection, dental clinics, eye, ear, nose and throat clinics, public health nurses, open air classes, and facilities for warm luncheons, athletics and recreation. Since provision is not made for these activities, it should, therefore, be the task of the teacher to attempt to remedy sanitary defects, and to recognize physical defects among the children. Much improvement can be obtained by enlisting the coopperation and interest of the parents and the community, through the parent-teacher associations and the other local organizations. In teaching the children habits pertaining to healthful living, it should be recognized that the instruction should be pleasant and interesting, and should if possible, be dramatized, in order to produce a lasting effect. Sometimes effective habits can be cultivated as a result of competition, or by offering marks, honors, or prizes. The children will also be willing to do many things out of love and respect for the teacher.
The book is well written and illustrated, and is simple and specific. In addition to the items already enumerated, it considers such questions as heating and ventilation, posture, common colds, the care of the teeth, eyes, ears, nose and throat, proper diet, play and physical education, and means for combating flies, mosquitoes, lice, rats and mice. The book will be found to be of particular value to the rural school teacher, who appreciates the important relationship of health to education, and who is anxious to do what she can to improve the health of the children, and the sanitation of the school.

\section{Murray P. Horwoood, M.S. \\ t}

Milk. Paul G. Heineman, Ph. D., Director of the Laboratories of the United States Standard Serum Company, Woodworth, Wis. Philadelphia and London: W. B. Saunders Company. Pp. 684, illustrated. Price, $\$ 6.00$ net.

An excellently written and up-to-date book on the subject of milk. As can be seen by the headings of the chapters it will be found useful to the sanitarian, the physician, the laboratory worker, the producer, the economist and the student. The subjects covered are historical, the physiology of lactation, physical properties of milk, general chemistry of milk, physical and chemical examination of milk, adulteration of milk, enzyms of milk, transmission of toxins and antibodies by means of milk, germicidal action of fresh cow's milk, microörganisms in milk, kinds of microörganisms in milk, fermented milk, bacteriological examination of milk, milk borne infections, certified milk, pasteurization of milk and other methods of reducing the germ content, control of milk supplies, economic aspect of milk production, milk in its relation to infant feeding, butter, cheese, ice-cream and ices, condensed and desiccated milks and milks from mammals other than the cow.

It is to be regretted that the author of such an excellent book should not have taken advantage of the opportunity to correct the prevalent opinion held that cow's milk has a much higher acidity than human milk. The erroneous statements as to the differences in the acidity of the two milks has been due to a lack of knowledge of the chemistry of milks and more recent investigations have shown, that the acidity of cow's milk is about a third of that usually given in the text-books upon the subject, 